\title{
Usefulness of Castor Oil for Bowel Preparation for Colon Capsule Endoscopy in the Patients on Dialysis
}

\author{
Naoki Hotta \\ Department of Internal Medicine, Division of Gastroenterology, Masuko Memorial Hospital, Aichi, Japan \\ Email: hotta4166@yahoo.co.jp
}

How to cite this paper: Hotta, N. (2017) Usefulness of Castor Oil for Bowel Preparation for Colon Capsule Endoscopy in the Patients on Dialysis. Open Journal of Medical Imaging, 7, 263-267.

https://doi.org/10.4236/ojmi.2017.74024

Received: November 14, 2017

Accepted: December 22, 2017

Published: December 25, 2017

Copyright $\odot 2017$ by author and Scientific Research Publishing Inc. This work is licensed under the Creative Commons Attribution International License (CC BY 4.0).

http://creativecommons.org/licenses/by/4.0/

\section{Open Access}

\begin{abstract}
Since Colon capsule endoscopy (CCE) was approved for reimbursement under the national health insurance system of Japan in January 2014. Dialysis patients are potentially susceptible to bleeding because of the fragile intestine, impaired platelet function, or oral administration of nonsteroidal antiinflammatory drugs (NSAIDs) or anticoagulants. Increasing experience with CCE different bowel preparation regimens have been used with variable results. The patient on dialysis has moisture restrictions. We experienced the case of the half a dose of the previous protocol by a method using the castor oil. In this study, we evaluated the efficacy of bowel preparation with castor oil for improving the capsule excretion rate. In 23 of 24 (95.8\%) patients capsule transit time and duration of capsule endoscopy were shortened. The results are presented and briefly discussed in this report.
\end{abstract}

\section{Keywords}

Castor Oil, Colon Capsule Endoscopy, Patients on Dialysis

\section{Introduction}

The incidence and prevalence of end-stage renal disease (ESRD) have been increasing worldwide. A previous study reported that ESRD patients tend to have various gastrointestinal lesions and associated complication [1]. In addition, the incidence of vascular lesions such as angioectasia has also been reported to be increases in these patients [2] [3] [4]. Colon capsule endoscopy [5] [6] [7] was approved for reimbursement under the national health insurance system of Japan in 2014. However, the capsule excretion rate after recommended bowel preparation reportedly ranges from $70 \%$ to $90 \%$, and administration of boosters 
is also necessary. For dialysis patients, liquid loading is a problem. At our hospital, the capsule excretion rate after recommended bowel preparation was 53\% in dialysis patients [8]. This article summarized the studies describing bowel preparation regimens for $\mathrm{CCE}$ assist gastroenterologists in preparation for a castor-oil regimen.

\section{Methods and Patients}

This study 28 dialysis patients who underwent colon capsule endoscopy at Masuko Memorial Hospital since March 2016. But 4 patients were discontinued according to patients hope. The remaining 24 patients ( 16 men and 8 women with rage 46 88 mean $67.2 \mathrm{y}$ was in Table 1. All enrolled patients were informed of the risks and complications Colon Capsule, such as capsule retention. Written informed consent was obtained from all patients. We excluded patient with those who had undergone abdominal radiotherapy, those with pacemaker insertion, those with severely hard stools. Colon capsule endoscopy was performed with PillCam COLON Capsule (Medtronic, Minneapolis, MN, USA). The recommended protocol of bowel preparation was modified (with administration of castor oil (Himashi Oil: Yoshida Pharmacentical, Japan)), and success rates of completing entire colon observation were compared. The modified regimen is shown in Table 2 [8]. The changes from the original regimen were as follows: Castor oil was administered immediately after capsule ingestion and as a booster at one and two hours later. The dose of castor oil was $30 \mathrm{ml}$ at each time point.

\section{Statistical Analysis}

Chi-squared test was performed for comparison between the castor oil-treated and castor oil-untreated groups. We weighed the fluid intake by the change of the injection method of the castor oil group. $P$ value of $<0.05$ was considered significant.

\section{Results}

The success rate in the castor oil-treated group was $95.8 \%$ (23/24), as shown in Figure 1. The maximal water intake of the fluid volume is $3900 \mathrm{ml}$. The average consumption in patients on dialysis was an average of (1500 - 3900) median $3171 \mathrm{ml}$, and the patients of the smallest water intake had $1250 \mathrm{ml}$ two patients. A utility is very high for the patient on dialysis with moisture restrictions. The success rate of completing entire colon observation was $63 \%$ in the castor

Table 1. Patient demographic data.

\begin{tabular}{|c|c|c|}
\hline \multicolumn{2}{|c|}{ All patients, n (\%) } & $24(100)$ \\
\hline \multicolumn{2}{|c|}{ Mean } & 67.2 \\
\hline \multicolumn{2}{|c|}{ Range } & $46-88$ \\
\hline \multirow{2}{*}{ Gender (\%) } & Female & 8 \\
\hline & Male & 16 \\
\hline
\end{tabular}




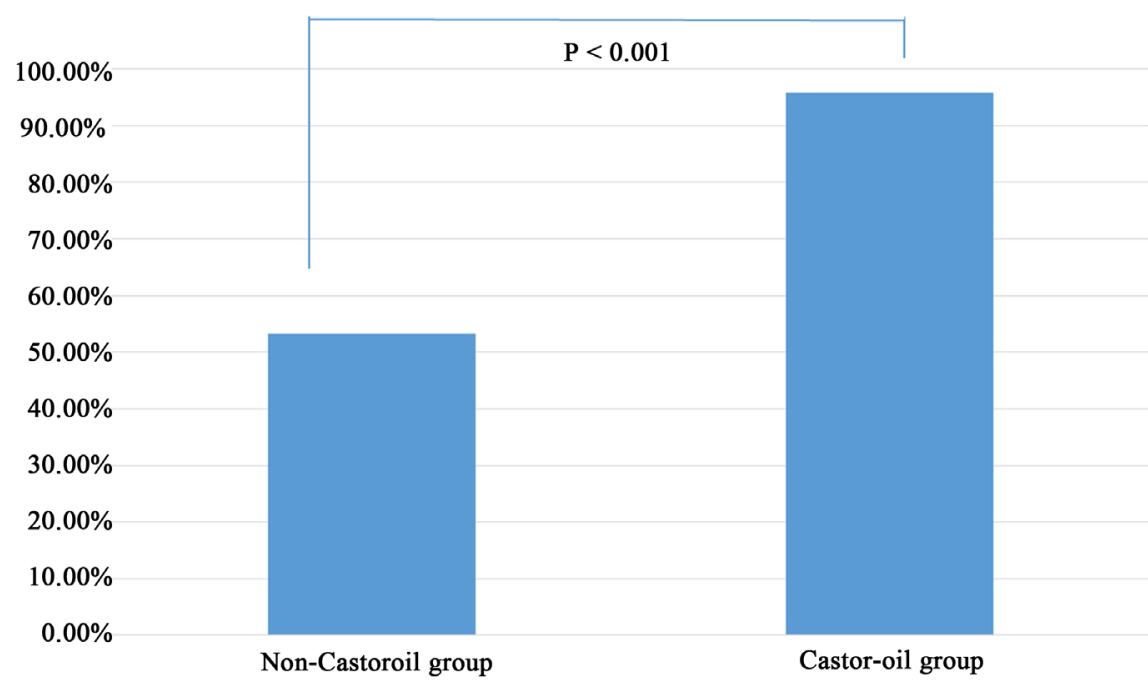

Figure 1. Colon capsule endoscopy. Complete visualization rate. Non castor oil group $54 \%$, castor oil used group $95.8 \%$.

Table 2. Bowel preparation regimen (Quoted from the table on page 105 of reference [8]).

\begin{tabular}{|c|c|c|c|c|}
\hline & & Day before endoscopy & \multirow{2}{*}{\multicolumn{2}{|c|}{ Liquid volume }} \\
\hline Time & Procedure & Regimen & & \\
\hline $\begin{array}{l}\text { Morning, noon, } \\
\text { and evening }\end{array}$ & Low-residue diet & Enimaclin & \multirow{3}{*}{ - } & \\
\hline $21: 00$ & Bowel cleansing & $\begin{array}{l}\text { Picosulfate sodium: } 1 \text { packet } \\
\text { Sennoside: } 2 \text { tablets }\end{array}$ & & \\
\hline After 21:00 & \multicolumn{3}{|c|}{ Fasting } & \\
\hline \multicolumn{5}{|c|}{ Day of endoscopy } \\
\hline Time & Procedure & Regimen & Liquid volume & total \\
\hline 9:00-11:00 & Bowel cleansing & $\begin{array}{l}\text { Moviprep (containing Gascon Drop): } \\
1.5 \mathrm{~L} \text { + water (or tea): } 0.75 \mathrm{~L}\end{array}$ & $2.25 \mathrm{~L}$ & $2.25 \mathrm{~L}$ \\
\hline Capsule ingestion & & $\begin{array}{l}\text { Ingest a capsule endoscope with Gascon: } \\
\qquad 4 \mathrm{~mL}+\text { water: } 0.1 \mathrm{~L}\end{array}$ & - & $2.25 \mathrm{~L}$ \\
\hline $\begin{array}{l}\text { Immediately after } \\
\text { capsule ingestion }\end{array}$ & & $\begin{array}{l}\text { Castor oil: } 30 \mathrm{~mL} \text {, intramuscular } \\
\text { injection of metoclopramide }\end{array}$ & - & - \\
\hline $\begin{array}{l}\text { After the capsule reaches } \\
\text { the small intestine }\end{array}$ & $\begin{array}{l}\text { Confirming the arrival } \\
\text { enhancing peristalsis }\end{array}$ & $\begin{array}{l}\text { No water intake but hard candy and gum is } \\
\text { allowed until the capsule endoscope reaches } \\
\text { the small intestine. Oral administration of mosapride: } \\
4 \text { tablets. Moviprep: } 0.25 \mathrm{~L}+\text { water (or tea): } 0.25 \mathrm{~L}\end{array}$ & $0.5 \mathrm{~L}$ & $2.75 \mathrm{~L}$ \\
\hline 1 hour later & Booster & $\begin{array}{l}\text { Castor oil: } 30 \mathrm{~mL} \text {, Teleminsoft suppository, } \\
\text { Moviprep: } 0.25 \mathrm{~L} \text { + water (or tea): } 0.25 \mathrm{~L}\end{array}$ & $0.5 \mathrm{~L}$ & $3.25 \mathrm{~L}$ \\
\hline 2 hours later & Booster & $\begin{array}{l}\text { Mosapride: } 6 \text { tablets, Magcorol P: } 1 \text { package }+ \text { water: } \\
0.45 \mathrm{~L} .{ }^{*} \text { Dialysis patients: Oral administration } \\
\text { of castor oil: } 30 \mathrm{~mL} \text {. Glycerol enema at 15:30. }\end{array}$ & $0.45 \mathrm{~L}$ & $3.7 \mathrm{~L}$ \\
\hline
\end{tabular}


oil-untreated group at our hospital (patient characteristics: 73 men and 29 women with mean age of 60 years, including 30 dialysis patients and 57 non-dialysis patients). The success rates were $70 \%$ in the non-dialysis patients and $54 \%$ in the dialysis patients) [8]. Statistically significant differences were observed between patients on Dialysis receiving bowel preparation with and without castor oil $(P<0.001)$.

\section{Discussion}

This study compared the discharge rate of the capsule endoscope in patients on dialysis.

Originally a ratio of constipation is high, and the patient on dialysis often uses laxative.

Because intestinal tract is compromised in addition to it, there is not little difficulty in the case to do for $\mathrm{CF}$ enforcement either. The discharge rate of the examination in our four patients on dialysis of the past was $100 \%$. However, we used the fluid volume average $3172 \mathrm{ml}$. However, $1250 \mathrm{ml}$ was included in the minimum two at an average of $2075 \mathrm{ml}$ for this examination case. It is thought that we change it for a method to have you take capsule endoscope from a point in time when two times of back-raking accepted the decrease in fluid intake. We can test that we reduce a fluid intake for patient on dialysis easily. It egested the patients whom it did not egest this time last time without using castor oil. We hated the testing very much, but, after the testing, appeared until the remark that you should have examined earlier. Also, there were the patients who detected polyps on this testing. There is also are port of a way using Gastrografin [9], the castor-oil, the cost is low. Castor-oil regimens were also possible to reduce the water intake. A gut of a dialysis patients embritles, and there is also a possibility that colon fiber perforates. Castor oil is useful for a booster of CCE to dialysis patients.

\section{Conclusion}

The booster method of the capsule endoscope using the castor oil is usually thought of effectively by a patient on dialysis having poor back-raking.

\section{References}

[1] (2011) US Renal Data System (USRDS) 2011 Annual Data Report: Atlas of Chronic Kidney Disease and End-Stage Renal Disease in the United States. National Institute of Health, National Institute of Diabetes and Digestive and Kidney Diseases, Bethesda, MD, USA.

[2] Kang, J.Y. (1993) The Gastrointestinal Tract in Uremia. Digestive Diseases and Sciences, 38, 257-258. https://doi.org/10.1007/BF01307542

[3] Etemad, B. (1998) Gastrointestinal Complications of Renal Failure. Gastroenterology Clinics of North America, 27, 875-892.

[4] Hosoe, N., Matsukawa, S., kanno, Y., et al. (2016) Cross-Sectional Small Intestinal Surveillance of Maintenance Hemodialysis Patients Using Video Capsule Endosco- 
py: SCHEMA Study. Endoscopy International Open, 4, E589-E596.

https://doi.org/10.1055/s-0042-105203

[5] Tajiri, H. (2011) Current Situation and Problems of Colon Capsule Endoscopy. Gastroenterological Endoscopy, 53, 2998-2999.

[6] Bouchard, S., Ibrahim, M. and Van Gossum, A. (2014) Video Capsule Endoscopy: Perspectoves of a Revolutionary Technique. World Journal of Gastroenterology, 20, 17330-17343.

[7] Kakugawa, Y., Saito, Y., Sato, S., et al. (2012) New Reduced Volume Preparation Regimen in Colon Capsule Endoscopy. World Journal of Gastroenterology, 18, 2092-2098. https://doi.org/10.3748/wjg.v18.i17.2092

[8] Hotta, N. (2016) The Use of Castor Oil for Bowel Preparation for Colon Capsule Endoscopy. Open Journal of Medical Imaging, 6, 103-107. https://doi.org/10.4236/ojmi.2016.64010

[9] Togashi, K., Fujita, T., Utano, K., et al. (2015) Gastrografin as an Alternative Booster to Sodium Phosphate in Colon Capsule Endoscopy: Safety and Efficacy Pilot Study. Endoscopy International Open, 3, E659-E661.

https://doi.org/10.1055/s-0034-1393075 